\title{
Radiation protection in interventional radiology
}

\author{
Proteção radiológica aplicada à radiologia intervencionista
}

Regina Moura' ${ }^{1}$ Fernando Antonio Bacchim Neto ${ }^{1}$

There has been continuous development in endovascular surgery over recent years. The advantages of this type of treatment are undeniable, since it offers reductions in length of hospital stay, in the volume of blood lost by patients, in the duration of anesthesia and in overall time taken for procedures.

Improvement in the techniques and materials employed has made possible recanalization of extensive occluded arterial segments and the exclusion of ever more complex aneurysms, greatly expanding the range of indications.

Nothing has prevented the growth of endovascular surgery: not the need for sophisticated radiological equipment or the high cost of materials. However, there has been little discussion of the consequences of radiation for the medical team or for the patients themselves.

Although there have already been studies of robotically conducted procedures in endovascular surgery, this method is still in the process of development and its cost is likely to be very high, not to mention that it will still take many years before the method can be adopted as routine. Few articles have been published in Brazil discussing the risks of the radiation emitted by radiological equipment, whether used for angiography or for angiotomography. To what extent should we be concerned about this?

This question should be answered with the help of other professionals, who can provide guidance in terms of measurements recorded with dosimeters or provide help with adjusting the radiation emitted by equipment. It is now recommended that occupational health teams, including medical physicists and biomedical engineers, should be involved in controlling radiology services.

Modern equipment offers good image quality, thereby reducing the number of radiological image acquisitions needed. There are numerous preoperative diagnostic imaging exams that are very accurate, such as Duplex Mapping, Computed Tomography and Magnetic Resonance Imaging. Still, endovascular treatments expose medical staff to large doses of radiation due to the proximity between physician and patient during the entire examination. This exposure tends to be even greater for professionals still being trained. It is known that radiation effects are cumulative and that definitive cell damage can have negative impacts on health. Radiation provokes oxidative stress, which can cause molecular and genetic damage, and this can have serious consequences over time, such as the development of neoplasms. ${ }^{1-3}$

Radiation protection is necessary in all circumstances in which radiation is applied in medicine, but even greater attention should be afforded to procedures guided by fluoroscopic images for professionals who remain in the room during the examination, ${ }^{3,4}$ such as technicians, anesthetists, nurses, etc. ${ }^{5}$

\section{USE OF DOSIMETERS}

Dose limiting is a well-defined practice in radiation protection for occupationally exposed individuals (OEIs). Each OEI should be monitored monthly to ensure that the doses received are not above the limits established. Frequent dose monitoring can reveal practices involving high exposures and thus determine the need for more objective and efficient radiological protection strategies. ${ }^{5}$ To increase the accuracy in dosimetry, the International Commission on Radiological Protection (ICRP) $)^{5,6}$ recommends the use of two dosimeters, one inside personal protection items and one on the outer layer. This provides a more reliable estimate of the doses received by professionals. ${ }^{5}$ Additional dosimeters can be used to measure doses in eye lenses and in the upper extremities. ${ }^{7}$

\section{DOSE LIMITS}

ICRP publications set forth recommendations on occupational dose limits that are accepted by most countries. These limits are expressed as effective doses for the whole body, and also as equivalent doses for particular regions or tissues of the professional's body. The limit for the effective dose is $20 \mathrm{mSv}$ per year (as an annual average over 5 years) and must not exceed $50 \mathrm{mSv}$ in a single year for the eye lens. The limit for extremities and the skin is $500 \mathrm{mSv}$ per year. ${ }^{7,8}$ However, occupational doses should be "as low as reasonably achievable", which is known as the ALARA principle of radiation protection. 


\section{TOOLS FOR RADIATION PROTECTION}

\section{Shielding of equipment}

Mobile shielding (screens) made of transparent plastic and lead are available for additional protection of OEIs and are particularly suitable for nursing and anesthesia personnel. ${ }^{9}$ Ceiling-hung shields, generally made from transparent leaded plastic should also be used for long duration procedures because they significantly reduce doses to the head and trunk, particularly to the lens of the eye. ${ }^{10}$ Lead drapes hung below the table, between the X-ray tube and the worker, significantly reduce the doses received and should always be used when possible.

\section{Personal shielding}

To decrease the release of radiation on the body of professionals, several personal protection items are available, such as aprons, goggles and thyroid protectors. Equipment should be in accordance with the stature of the professional, so as to avoid ergonomic problems and to improve protection. ${ }^{11,12}$

Because cataract induction may be a stochastic effect, i.e., the probability of occurrence is proportional to radiation dose exposure, it is advisable to wear glasses with lead lining to protect the crystalline lens, particularly when shields hung from the ceiling are not available. ${ }^{2}$ Lead gloves may appear a useful protection against radiation for situations in which the operator's hands are in the direction of the primary radiation beam. However, they should be employed with caution to avoid an increase in the radiation dose due to the fluoroscopy system's automatic exposure control, which will compensate for the presence of additional attenuating material. Therefore, lead gloves are not recommended, and the best solution is to maintain hands in the direction of the beam for as short a time as possible. ${ }^{13}$

\section{Scattering of radiation}

Many factors can influence the distribution and intensity of scattered radiation, such as patient size, angle of the image acquisition system, use of shields, and methods of fluoroscopy. In a typical procedure situation (when the system is not angled and an anterior posterior projection is employed), the intensity of scattered radiation is higher in regions below the table height. ${ }^{14,15}$ Shorter OEIs will receive more scattered radiation than taller OEIs and should therefore be kept further from the radiation source. If the distance between the worker and the radiology table is doubled, radiation exposure will drop to one quarter of the initial value.

\section{HOW TO MINIMIZE RISKS}

\section{Low doses for patients provide low doses for professionals}

Reducing the patient's dose will proportionally reduce the dose received by the OEIs. ${ }^{6}$ It is recommended that short fluoroscopy sequences rather than prolonged operation be used. The freeze image facility can also significantly reduce redundant images of the same anatomic region.

Fluoroscopy equipment offers image acquisition modes that help to reduce patient doses. Currently, the most common resources available in the equipment are: removal of the anti-scatter grid (when possible), low-dose image modes, automatic exposure control, and low frame rate. ${ }^{6}$ All OEIs should be given training in operational safety practices.

\section{Correct position of the equipment}

The patient should be positioned as far as possible from the X-ray tube. The image receptor should be as close as possible to the patient. ${ }^{6}$

\section{Use of collimation}

Collimation should be adjusted so that only the area of interest is irradiated. Good collimation can reduce doses received by the professional and by the patient and also improves image quality by reducing radiation scatter. ${ }^{6}$

\section{Correct positioning in the room}

Scattered radiation levels are highest in regions close to the equipment, so all OEIs should stay as far as possible from these regions. For this purpose, using tube extensions and/or needled holders and leaving the procedure room during the acquisition can help to substantially reduce occupational doses. ${ }^{6}$

When the system is angled, the largest scattered radiation region is closest to the $\mathrm{X}$-ray tube. Workers should stay opposite to the X-ray tube. Therefore, previous planning of the procedures is of great importance.

\section{Dosimetry in routine clinical practice}

At our institution a study of the readings from the dosimeters of residents and their supervisors indicated that professionals wearing radiation protection did not exceed annual dose limits during normal routines. Our analysis also showed that personal dosimeters placed at the thorax underestimated the doses received, when compared with other parts of the interventional physician's body, particularly the abdomen and lower limbs. This is because radiation 
Table 1. Number of procedures that a properly protected professional can perform without exceeding annual limits. Procedures that can be performed more than 2,500 times per year were considered not to have a limit.

\begin{tabular}{cccc} 
& \multicolumn{3}{c}{ Principal interventional professional } \\
\cline { 2 - 4 } & Thorax & Crystalline lens & Extremities \\
\hline Angiographs & 1,080 & No limit & No limit \\
Angioplasties & 390 & 970 & No limit \\
A. A. A. & 60 & 140 & 240 \\
\hline
\end{tabular}

A. A. A.: treatment of abdominal aortic aneurysms.

scatter is predominantly from beneath the table, due to reflections from the patient.

It is recommended that professionals be rotated and that dosimeters be placed at extremities and close to the eyes.

The results obtained were used to estimate the maximum number of procedures that each professional could conduct per year without exceeding annual limits for the thorax, crystalline lens and extremities (study in publication). The results were obtained considering the efficacy of radiation protection for the trunk and eye lens. Procedures for which the results indicated more than 2,500 procedures per year were considered not to have limits. These results will not be the same for all institutions and should only be seen as a guide. The results are shown in Table 1.

\section{REFERENCES}

1. Miller DL. Overview of contemporary interventional fluoroscopy procedures. Health Phys. 2008;95(5):638-44. http://dx.doi. org/10.1097/01.HP.0000326341.86359.0b. PMid:18849697.

2. Vano E, Gonzalez L, Fernández JM, Haskal ZJ. Eye lens exposure to radiation in interventional suites: caution is warranted. Radiology. 2008;248(3):945-53. http://dx.doi.org/10.1148/radiol.2482071800. PMid:18632529.

3. Kim KP, Miller DL, Gonzalez AB, et al. Occupational radiation doses to operators performing fluoroscopically-guided procedures. Health Phys. 2012;103(1):80-99. http://dx.doi.org/10.1097/ HP.0b013e31824dae76. PMid:22647920.

4. World Health Organization. Institut für Strahlenhygiene des Bundesgesundheitsamtes. Efficacy and radiation safety in interventional radiology. Geneva: World Health Organization; 2000. 90 p.

5. Valentin J. Avoidance of radiation injuries from medical interventional procedures. Ann ICRP. 2000;30(2):7-67. http://dx.doi.org/10.1016/ S0146-6453(01)00004-5. PMid:11459599.

6. Miller DL, Vañó E, Bartal G, et al. Occupational radiation protection in interventional radiology: a joint guideline of the Cardiovascular and Interventional Radiology Society of Europe and the Society of Interventional Radiology. Cardiovasc Intervent Radiol. 2010;33(2):230-9. http://dx.doi.org/10.1007/s00270-009-9756-7. PMid:20020300.

7. Whitby M, Martin CJ. A study of the distribution of dose across the hands of interventional radiologists and cardiologists. Br J Radiol.
2005;78(927):219-29. http://dx.doi.org/10.1259/bjr/12209589. PMid:15730986.

8. Comissão Nacional de Energia Nuclear - CNEN. CNEN-NN-3.01: diretrizes básicas de proteção radiológica. Brasília; 2011.

9. Luchs JS, Rosioreanu A, Gregorius D, Venkataramanan N, Koehler $\mathrm{V}$, Ortiz AO. Radiation safety during spine interventions. J Vasc Interv Radiol. 2005;16(1):107-11. http://dx.doi.org/10.1097/01. RVI.0000142596.16611.0C. PMid:15640417.

10. Maeder M, Brunner-La Rocca HP, Wolber T, et al. Impact of a lead glass screen on scatter radiation to eyes and hands in interventional cardiologists. Catheter Cardiovasc Interv. 2006;67(1):18-23. http:// dx.doi.org/10.1002/ccd.20457. PMid:16273590.

11. Klein LW, Miller DL, Balter S, et al. Occupational health hazards in the interventional laboratory: time for a safer environment. J Vasc Interv Radiol. 2009;20(2):147-52, quiz 53. http://dx.doi. org/10.1016/j.jvir.2008.10.015. PMid:19062308.

12. Detorie N, Mahesh M, Schueler BA. Reducing occupational exposure from fluoroscopy. J Am Coll Radiol. 2007;4(5):335-7. http://dx.doi.org/10.1016/j.jacr.2007.01.018. PMid:17467618.

13. Wagner LK, Mulhern OR. Radiation-attenuating surgical gloves: effects of scatter and secondary electron production. Radiology. 1996;200(1):45-8. http://dx.doi.org/10.1148/radiology.200.1.8657942. PMid:8657942.

14. Balter S. Radiation safety in the cardiac catheterization laboratory: basic principles. Catheter Cardiovasc Interv. 1999;47(2):229-36. http://dx.doi.org/10.1002/(SICI)1522-726X(199906)47:2<229::AIDCCD23>3.0.CO;2-W. PMid:10376512.

15. Balter S, Sones FM Jr, Brancato R. Radiation exposure to the operator performing cardiac angiography with $U$-arm systems. Circulation. 1978;58(5):925-32. http://dx.doi.org/10.1161/01. CIR.58.5.925. PMid:699261.

$$
\begin{array}{r}
\begin{array}{r}
\text { Correspondence } \\
\text { Regina Moura }
\end{array} \\
\text { Rua Adolfo César, 126 - Jardim Eldorado } \\
\text { CEP 18608-780 - Botucatu (SP), Brazil } \\
\text { Tel.: +55 (14) 3882-9795 / +55 (14) 98141-2241 } \\
\text { E-mail: rmoura@fmb.unesp.br }
\end{array}
$$

Author information RM - Board-certified in Vascular and Endovascular Surgery from Sociedade Brasileira de Angiologia e de Cirurgia Vascular (SBACV)

PhD; assistant professor of Vascular and Endovascular Surgery at Faculdade de Medicina de Botucatu, Universidade Estadual Paulista (UNESP). FABN - Graduate student in Medical Physics at the Department of Biophysics, Instituto de Biociências, Universidade Estadual Paulista (UNESP). 